\title{
Impact of Distributed Generation Technology \& Operation Techniques on Distribution System Reliability
}

\author{
Ayman B. Attya ${ }^{1}$, Yasser G. Hegazy*,1 and Mahmoud A. Mostafa ${ }^{2}$ \\ ${ }^{1}$ German University in Cairo; ${ }^{2}$ Ain Shams University in Cairo, Egypt
}

\begin{abstract}
The research work done in this paper is directed into two main routes. The first one is evaluating the impact of different conventional and renewable types of generation techniques on distribution systems' reliability. The second route is developing an appropriate algorithm to model the operation schedules of distributed generators to obtain realistic and applicable reliability analysis for distribution systems integrated with distributed generators. Case studies are offered and the results obtained are presented and discussed.
\end{abstract}

Keywords: Distribution system reliability, seasonal operation, random operation, reliability indices, monte carlo simulation.

\section{INTRODUCTION}

Electrical power interruptions lead to economical, social losses and even human lives may be lost due to a power failure. Testing the performance of an electrical system was the objective of many research efforts, trying to formulate equations and identify parameters through which electrical engineers can judge whether this system is performing well or not. In other words; the system is reliable or not. Reliability is quantified by means of certain indices. These indices look into the system performance by computing the durations of interruptions and their frequency of occurrence. Analytical and simulation techniques were suggested to evaluate these indices in previous literatures. Many forms and equations were suggested to obtain the reliability indices; by the year 2001 IEEE [1] has approved standard definitions and equations to explain and to calculate the reliability indices. Perfect reliability could be reached but large amounts of investments should be guaranteed to realize this target. Distributed generation (DG) is considered a potential investment that leads to enhancement of the system reliability. Applications of DG include; continuous power, combined heat and power, peaking power, green power and premium power. DG is mainly characterized by; quick start-up, low installed cost and low fixed and maintenance cost [2-4].

Several publications attempted to address the reliability issues of the DG systems [5-9]. Hegazy et al. [10, 11] presented a Monte Carlo based technique for the assessment of the adequacy and the security of distributed generation systems. Their conducted analyses led to the estimation of the typical reliability indices of the new structured system. Chowdhury, et al. [12] developed a reliability model for determining the DG equivalence to a distribution facility for use in distribution system planning studies. Dugan et al. [13], Brown et al. [14], Mc Dermott et al. [15] are among several other publications that focused on the analysis of the impacts of the DG on the overall system reliability.

*Address correspondence to this author at the Associate professor at the faculty of Information Engineering Technology, German University in Cairo. Egypt; Tel: 2-7589990-8; Fax: 2-7581041;

E-mail: Yasser.higazi@guc.edu.eg
Most of the recent literatures focused on the capacity gain due to the installation of DG without paying attention to the effect of the generation technology (GT) used for this DG on the overall system reliability. Moreover, the impact of the operation schemes of the DG units on the system reliability didn't thoroughly investigated.

This paper aims to investigate the effects of the GT and the operation schedules of DG units on the system reliability. Both conventional and renewable generation techniques are highlighted. The limitations on the working hours of DG units due to the seasonal load variations are also addressed.

The work done in this paper is organized as follows: Section II, highlights the methodology adopted for ranking the GT from reliability point of view. Reliability indices are calculated in Section III for different combinations of GT to achieve the best reliability level of the system under study. The impact of the seasonal load variations on the working hours of the DG units and thus the reliability indices is investigated in Section IV. Finally, conclusions are offered in Section V.

\section{GENERATION TECHNOLOGY RANKING}

In this section, analyses were conducted to judge the impact of the GT of the distributed generation units, connected to distribution systems, on the overall system reliability. The data for the different generation technologies provided by the IEEE reliability test system (IEEE-RTS) [5] is adopted for conducting the intended analyses.

The conducted analyses were done in two directions. The first direction examines the sensitivity of the system adequacy to the GT used and rank the GT accordingly. For this purpose, the adequacy of the IEEE RTS is evaluated by applying an organized mixing of different types of GTs. The IEEE-RTS suggested 4 types of GTs namely; Combustion generation stations, Fossil generation stations, Hydro generation stations, and nuclear generation stations. In addition, wind turbine generators are included in this study to represent the renewable energy generators. The comprehensive data of the studied system is given in the appendix A.1. 
Comparisons are held between five types of GTs including wind power.

The second direction concerns with the evaluation of load point indices for a typical distribution feeder with the GT of the DG units connected to the system are chosen according to obtained ranking. The procedures conducted and the results obtained are discussed in the following subsections.

\section{II.1. Modeling Conventional DG Units}

For all the different types of the adopted GT, a two-statemodel (up state and down state) is used to model the operation of each DG unit. Fig. (1) shows an example of a twostate-model. The up state indicates that the DG is in its operating state and the down state implies that the element is inoperable due to a failure or a scheduled off. In this figure, TTF is the time to failure and TTR is the mean time to repair. This model is used to provide an artificial operating history of each DG unit in the form of an up-and-down cycle.

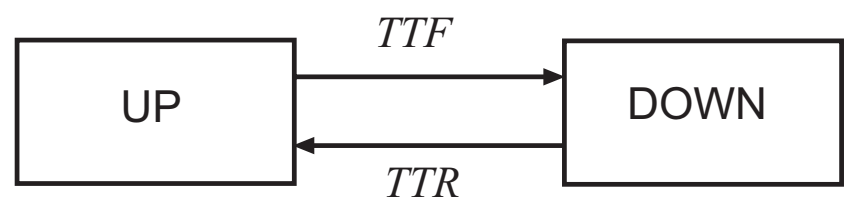

Fig. (1). Two state model of a DG unit.

The operating cycles of all the DG are combined to obtain the power capacity of the DG units. This is then added to the station units in order to obtain the overall available capacity of the system. The system available capacity operating history is superimposed on the chronological hourly load operating history to obtain the system available margin model. The estimate for the average energy not supplied per hours is then calculated using Monte Carlo simulation method. The procedure presented in $[7,11]$ is employed for this purpose.

\section{II.2. Modeling Wind Turbine Generators}

Wind turbine generators (WTG) are widely used in power systems for their attractive economical benefits. To integrate this generation technology with the current analyses, equations introduced in [6] to simulate the input - output characteristics of the wind turbine generator are employed. To determine the number of WTG units in a wind farm with certain ratings; the overall rating of the wind farm is divided by the rating of a single WTG unit. A $2.5 \mathrm{MW}$ wind turbine generator with specifications shown in Table A.2 is adopted for the analyses conducted in this paper. The power characteristics of this wind turbine is given in Table A.3.

\section{II.3. Applications}

In this section, several applications are conducted to determine how much the DG generation technology would affect the average unsupplied load per hour in the system under study.

\section{II.3.1. Single GT}

Only one type of GT feeds the whole load of the IEEERTS through each case study with the size, number of the
RTS generators and system demand kept the same. The MTTF and MTTR of the used GT are applied for all the other generation stations with each generation unit represented by its rated capacity. For each generation unit a state duration curve is generated within a certain time for each sample, and then all the chronological operating history are summed together to form the generation chronological operating history. The Average Power Not Supplied (APNS) index is calculated using (1) and is used to judge the system adequacy with the applied GT. The time span of the chronological operating history is 8760 hours which is equivalent to one year. The convergence of Monte Carlo simulation yields the prediction the value of the APNS. Table 1 summarizes the results obtained for this case study.

$A P N S=\frac{\sum_{1}^{8760}\left(P_{G i}-P_{L i}\right) \times 1}{8760}$

Where $\mathrm{P}_{\mathrm{G}}$ is the generated power at a hour $\mathrm{I}$ and $\mathrm{P}_{\mathrm{L}}$ is the load at this hour.

Table 1. Sing GT Results

\begin{tabular}{|c|c|}
\hline Technology & APNS (MW/hr/year) \\
\hline \hline Hydro & 0.0218 \\
\hline Fossil (Oil) & 1.1269 \\
\hline Fossil (Coal) & 1.8555 \\
\hline Combs. & 10.136 \\
\hline Nuclear & 16.915 \\
\hline
\end{tabular}

It can be derived from Table 1 that Hydro GT recorded the least APNS which Nuclear GT has got the highest APNS. This is mainly due to the long restoration time of the nuclear station when it fails.

\section{II.3.2. Combination of Different GT}

Mixing GT was done as follows: Each GT was considered as a base one to feed the RTS and only one generation set based on another GT is kept constant without changing its MTTF and MTTR to the corresponding values of the base GT used. For example; if the notation of the used GT is Hydro-Nuclear this means that the base technology of generation is the nuclear one while hydro GT is kept as it is. Table 2 shows an example of the mixing strategy for five generators where the nuclear is the base and it is mixed with hydro.

Table 2. Data of the Hydro-Nuclear Case Study

\begin{tabular}{|c|c|c|c|c|}
\hline Set no. & Capacity(Mw) & GT & MTTF & MTTR \\
\hline \hline 1 & 12 & Nuclear & 1100 & 150 \\
\hline 2 & 20 & Nuclear & 1100 & 150 \\
\hline 3 & 50 & Hydro & 1980 & 20 \\
\hline 4 & 76 & Nuclear & 1100 & 150 \\
\hline 5 & 100 & Nuclear & 1100 & 150 \\
\hline
\end{tabular}


Table 3 gives the estimated APNS (MW/hr/year) for the IEEE_RTS with the pre-described mixing strategy applied. Generally the hydro GT improved the APNS when it was used as base GT. On the other hand the Combustion GT proved a poor performance; it recorded. In addition, Results confirm that using Nuclear GT as a base GT leads to poor APNS. While using Hydro GT as an aiding GT with any other GT other than Nuclear improves the APNS for this system.

Table 3. Mixing Conventional GT Results

\begin{tabular}{|c|c|c|c|}
\hline Technology & APNS & Technology & APNS \\
\hline \hline Combs._Hydro & 0.0241 & Fossil (Oil)_Fossil(Coal) & 3.3205 \\
\hline Fossil (Oil)_Hydro & 0.0643 & Fossil (Coal)_Combs. & 5.7547 \\
\hline Fossil (Coal)_Hydro & 0.14 & Fossil (Oil)_Combs. & 6.5977 \\
\hline Hydro_Fossil (Oil) & 1.0936 & Hydro_Combs. & 8.5439 \\
\hline Nuclear_Hydro & 1.098 & Fossil(Coal)_Nuclear & 9.3175 \\
\hline Combs._Fossil (Oil) & 1.2067 & Fossil (Oil)_Nuclear & 10.448 \\
\hline Combs._Fossil (Coal) & 1.9392 & Nuclear_Combs. & 11.962 \\
\hline Hydro_Fossil (Coal) & 2.0992 & Hydro_Nuclear & 14.135 \\
\hline Nuclear_Fossil (Coal) & 3.143 & Combs._Nuclear & 16.871 \\
\hline
\end{tabular}

The results of wind energy involvement in the system with the GTs which achieved good performance based on the results of mixing conventional GTs are displayed in Table $\mathbf{4}$. Wind energy decreased the quality of all the systems which was applied. For example a system which was totally based on Hydro GT the average APNS was increased from 0.0216 $\mathrm{MW} / \mathrm{hr} /$ year up to $0.042 \mathrm{MW} / \mathrm{hr} / \mathrm{year}$ and as the capacity of the generation set was increased the performance turned to be worse $(0.4252 \mathrm{MW} / \mathrm{hr} / \mathrm{year})$. The same effect was obtained from the other iterations as it is clear from the comparison between the results obtained with and without an integrated wind farm.

Table 4. Mixing Conventional GT with Wind Generators

\begin{tabular}{|c|c|c|}
\hline Generation set replaced/GT & No. of WTG used & APNS \\
\hline \hline No.2/(Hydro) & 32 & 0.0389 \\
\hline No.8/(Hydro) & 140 & 0.9111 \\
\hline No.1/(Hydro_Nuclear) & 24 & 16.411 \\
\hline No.3/(Fossil coal) & 120 & 7.3761 \\
\hline
\end{tabular}

\section{CALCULATIONS OF RELIABILITY INDICES}

The system under study is a typical distribution feeder formed of 3 load points A, B and C as shown in Fig. (2). Laterals contain fuses to isolate the failed sector from the rest of the system, but a switching time is needed to restore the supply after any fault occurs in the system. The main feeders are equipped with isolation switches to improve the reliability of the system. In this study, load point indices, CAIDI and CAIFI in addition to system reliability indices
SAIDI and SAIFI are calculated in order to assess the impact of GT on the reliability from the customer perspectives. The procedure presented by the authors in [8] is implemented for this purpose and the following cases are implemented:

Case A: The main supply is considered to be fully reliable in other words never interrupted. Generally, this is not a practical case but the results obtained using this assumption is taken as reference to compare the results of the other cases. No alternative supply is applied in this case.

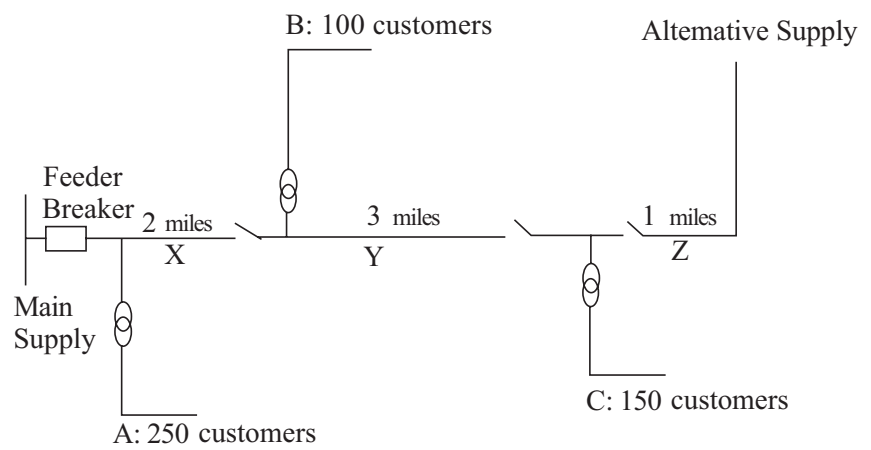

Fig. (2). Radial test feeder under study.

Case B: Single supply is used to provide all loads with electric power. The following technologies are studied; Hydro, Fossil steam (oil fueled) and Nuclear. These three GTs were selected based on the previously obtained results. Each GT is examined alone to compare the obtained results.

Case C: The main supply is hydro while the alternative one is a combustion turbine.

Case D: The main supply is a hydro, but a wind energy farm is deployed as an alternative supply.

Cases $\mathrm{C}$ and $\mathrm{D}$ represent the alternative supply as an online running reserve. When a failure happens it will be able to feed the loads immediately without any starting time. Only the switching periods will be considered. The alternative supply support each load point with another path for power delivery, so if any of these two paths are available the load will not be interrupted, but there will be an interruption during the switching process from the main supply to the alternative supply path. System reliability data are shown in the appendix (Table A.4).

Table 5 shows the calculated reliability indices for the feeder under study for the underlying study cases. Hydro GT led the system to a performance very near to its performance if a wind energy farm is connected as a backup supply, for example; the CAIDI in case D is 0.2175 hours, while when a hydro generation station is connected the CAIDI is 0.2722 hours, the difference is about 0.016 hours. On the other hand the Fossil steam (oil fueled) GT recorded least interruption frequency (0.0285) after that of hydro but with a poor interruption duration. This supports the point view that nuclear stations need longer time for maintenance or repair.

Oil GT recorded moderate values for both; load point indices and system indices, as a conclusion nuclear GT 
Table 5. Reliability Indices Values

\begin{tabular}{|c|c|c|c|c|c|c|}
\hline Case/ Indices & $\mathbf{A}$ & $\mathbf{B}($ hydro) & B(oil) & B(nuclear) & C \\
\hline \hline CAIDI & 0.00054 & 0.2722 & 1.2146 & 3.6746 & 0.0216 & 0.2175 \\
\hline CAIFI & 0.00055 & 0.0176 & 0.0285 & 0.0292 & 0.0026 & 0.0213 \\
\hline SAIDI & 0.00083 & 0.4067 & 1.8156 & 5.5207 & 0.0425 & 0.3523 \\
\hline SAIFI & 0.00085 & 0.0262 & 0.0428 & 0.0434 & 0.1615 & 0.0300 \\
\hline
\end{tabular}

causes less number of interruptions while hydro GT decrease the duration of interruption but with a higher density of occurrence.

Alternative supply improved the performance of system from the point of view of duration based indices for example SAIDI was reduced by about five hours when a combustion turbine station was applied as a backup supply to the main hydro supply (case B and C). Switching from the main supply to the alternative one increased the frequency of occurrence of interruptions if compared to the cases that do not a backup supply. Wind farms have recorded the highest interruption times per the simulation sample in the CAIFI and SAIFI. Many other factors affect the wind generation stations; the temperature, the air density, and of course the wind speed. Consequently, the wind generation stations are not always capable of supplying the system or a certain load point with the required level of power; this will lead to many interruptions. But in overall the interruption duration is less if compared to a system that does not have any backup supply. Therefore the combustion turbine station when used as an alternative generator caused less number of interruptions than that of wind GT. Monte Carlo simulation convergences of CAIDI and SAIFI for some cases of study are shown in Figs. (3 and 4).

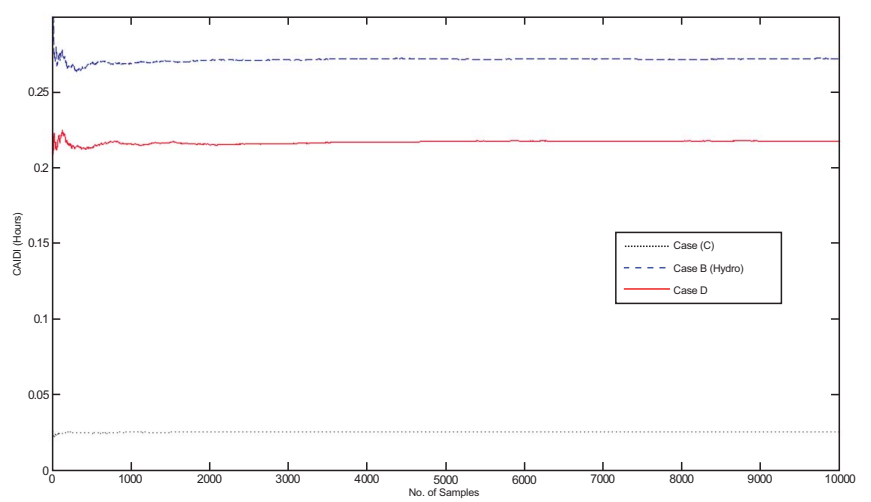

Fig. (3). Monte Carlo simulation for CAIDI of cases B (Hydro), C and D.

\section{DISTRIBUTED GENERATION OPERATION TECHNIQUES}

DG units can operate for a pre-defined number of hours per each month or week or even on a daily bases. The num- ber of hours of operation depends on the demand within the different seasons of the year. In hot countries, the demand variation mainly occurs between summer and winter, the load may increase or decrease according to the climate of the country where the system is studied. It is assumed that we are dealing with a hot country where the summer load is greater than the winter load and each DG is scheduled to operate for only $25 \%$ of the year (about 2180 hour). In this research, two methods of distributing these operation hours over the year are implemented. The first method is a deterministic method where the DG unit is scheduled to operate for limited hours per week or per month with the summer working hours representing $60 \%$ of the year and the winter working hours are the remaining $40 \%$. The second method is a probabilistic method where the uncertainty in the operating state (on or off) of each DG unit is considered and the system reliability is calculated based on stochastic analysis.

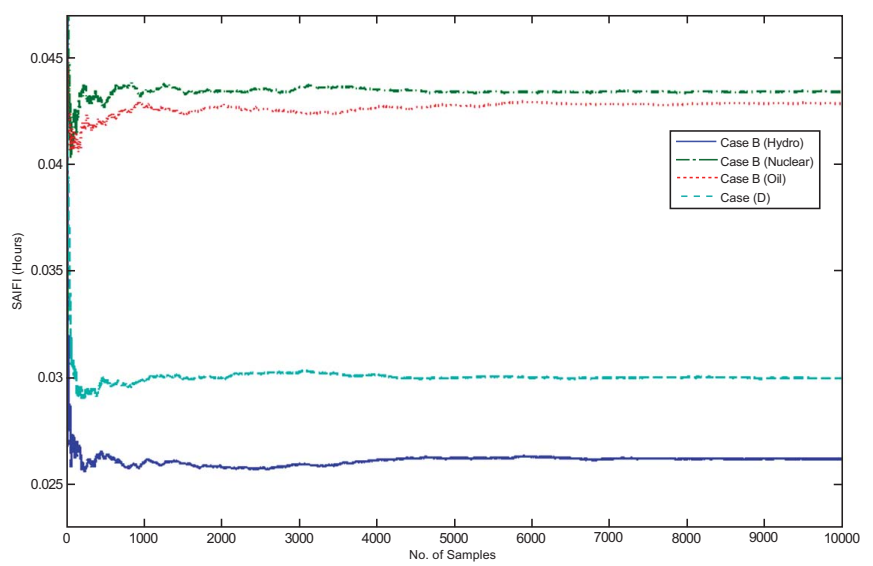

Fig. (4). SAIFI indices for Case B and Case D.

\section{IV.1. Deterministic Operating Hours}

The target operation duration is divided by the 52 weeks of the year for weekly operation or by the 12 months for monthly operation. For simplicity, each year is divided into 6 months of summer (starting from April to September) and 6 months of winter (the rest months of the year). Accordingly, for weekly limited operation, each DG unit shall work for 54.75 hours within one week during the summer and 36.5 hours weekly working time during the rest of year, while the monthly hours are 219 and 146 hours for summer and winter respectively.

The following procedure is applied to estimate the customer average interruption duration index (CAIDI) with the limited hours per season is applied: 
1. Generate the chronological operating history of the main supply and the other system components (main and lateral feeders), using the procedure presented by the authors in [9] for a mission period of one year (8760 hours).

2. Generate the chronological operating history of the DG units connected to the system, taking into consideration the limitation of the working time of each which differs according to the weekly or the monthly scheme as explained previously. The MTTF and the MTTR average weekly or monthly values are obtained by dividing their given values by 52 (no. of weeks/year) or 12(no. of months/year) respectively. For example if hydro DG is connected the given value of MTTF for this type is 1980 hours, if monthly sampling is applied its value should be 165 hours. Fig. (5) shows the chronological operating history of a DG within the first 5000 hours of a year.

3. Add all the chronological operating history that connects each load point to its supply to obtain a chronological operating history of the point itself. Note that any failure for one component or more will cause the interruption of power transmitted to the load point under investigation.

4. Run Monte Carlo simulation to estimate the CAIDI.

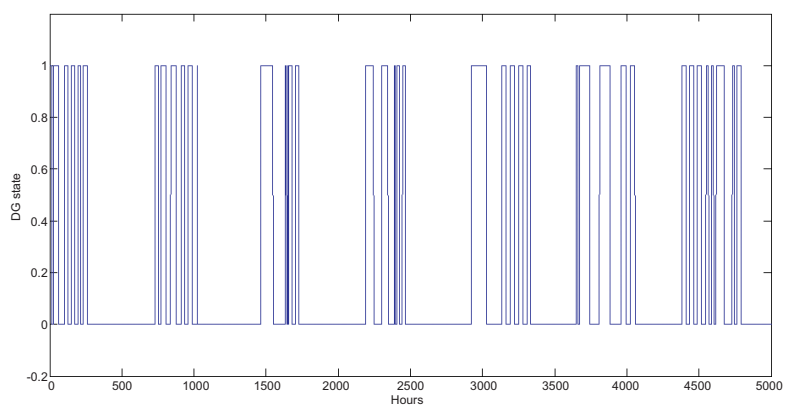

Fig. (5). Chrnological operating history for a DG (monthly limited operation/ Box and Muller dist.).

In this procedure several probability distributions functions (pdfs) were examined to generate the chronological operating history of each DG; these distributions are:

- $\quad$ Exponential (the default distribution used through out this research work).

- Box and Muller (a method to get Normal distribution).

- Log Normal.

- Wiebull (different values for freedom factor $(\beta)$ are tested), Gamma (different values for freedom factor $(\beta)$ are tested).

The defining equations of these distributions are given in Appendix A.

\section{IV.2. Random Operating Hours}

The locations of DG units are determined by the customers and are known to the utility; however, the instant of switching on and off of each DG is based on the customer's needs. Different customers would have different strategies for operating their DG and accordingly, the process of turning on and off each DG unit will be a random process. The random on and off cycle of each DG will result in a random contribution of this DG to the system power capacity. Consequently, the overall system power capacity will vary randomly and the determination of this capacity requires proper modeling of the random operation state of the system.

In this paper, the following procedure [9] is implemented to account for the random operation of the DG units:

1. Generate a random integer (m) between 0 and (n), where $\mathrm{n}$ is the number of available DG units connected to the system under study and $\mathrm{m}$ is the number of the DG units that are turned on during a certain sampling period.

2. Randomly select the $m$ busses that are connected to the $\mathrm{m}$ generators in their on state. The expression on does not mean by necessity that the DG is in up state during the whole sampling period but it means that its chronological operating history is involved when the chronological state operating history of the required load point is evaluated.

3. Form the generators/load point matrix (G/Lpt). This matrix is an $(\mathrm{m}+1)^{*}(\mathrm{~T})$ matrix where each row represents the chronological operating history of the path between the load point under study and one DG from the group which is turned on, and the columns $\mathrm{T}$ is the sampling period of each simulation shot of the DG. (T) May be 168 and 730 hours in case of weekly and monthly simulation respectively. Equation (2) gives an example of this matrix.

G / Lpt. $=\left(\begin{array}{l}\text { Main supply } \rightarrow \text { path to } \rightarrow \text { Load point A } \\ \text { DG1 } \rightarrow \text { path to } \rightarrow \text { Load point A } \\ \text { DG2 } \rightarrow \text { path to } \rightarrow \text { Load point A } \\ \downarrow \\ \text { DGn } \rightarrow \text { path to } \rightarrow \text { Load point A }\end{array}\right)$

4. Sum the entire matrix rows to obtain a vector which of the chronological operating history of the target load point.

5. Evaluate the load point index (CAIDI).

The following assumptions were made throughout the highlighted procedure:

- $\quad$ The main supply yearly chronological operating history is generated on a single shot with a sampling period of 1 year ( 8760 hours), assuming that the main supply is turned during the whole year.

- $\quad$ the components yearly chronological operating history are also generated on a single shot with a sampling period of 1 year ( 8760 hours).

- The DG units yearly chronological operating history are generated on a certain number of shots, this number depends on the sampling period. Weekly sampling mode (168 hours) needs to perform 52 weekly 
chronological operating histories to get the yearly chronological operating history of each DG.

- The required indices are calculated at the end of each year, using Monte Carlo simulation.

\section{IV.3. Case Study}

The radial feeder shown in Fig. (2) is adopted for this study with a second alternative supply is connected at the switch joining the lateral load point B with the main feeder. The study aims to estimate the CAIDI at different load points using the deterministic working hour's scheme and the random operating hour's scheme. The data used for this case study is found in Table 6.

\section{Table 6. Case Study DG Data}

\begin{tabular}{|c|c|c|}
\hline Generator & Technology & Sampling time \\
\hline \hline Main Supply & Hydro & 8760 \\
\hline Alternative I & Comb. Turbine & 730 \\
\hline Alternative II & Comb. turbine & 730 \\
\hline
\end{tabular}

Table (7) presents a comparison between the estimated CAIDI at load point "A" for different probability distribution functions under the application of both the deterministic and the random operating hours schemes. Fig. (6) depicts Monte

Table 7. A Comparison Between the Estimated CAIDI at Load Point A

\begin{tabular}{|c|c|c|c|}
\hline \multicolumn{2}{|c|}{ PDF } & CAIDI & CAIDI \\
DG I & DG II & Deurs/year) & $\begin{array}{c}\text { Dours/year }) \\
\text { Random }\end{array}$ \\
\hline \hline Wiebull $(\beta=5)$ & Gamma $(\beta=5)$ & 0.1741 & 0.1482 \\
\hline Wiebull $(\beta=5)$ & Wiebull $(\beta=5)$ & 0.2034 & 0.1513 \\
\hline Wiebull $(\beta=5)$ & Box and Muller & 0.1725 & 0.0821 \\
\hline Wiebull $(\beta=5)$ & Exponential & 0.1732 & 0.1383 \\
\hline
\end{tabular}

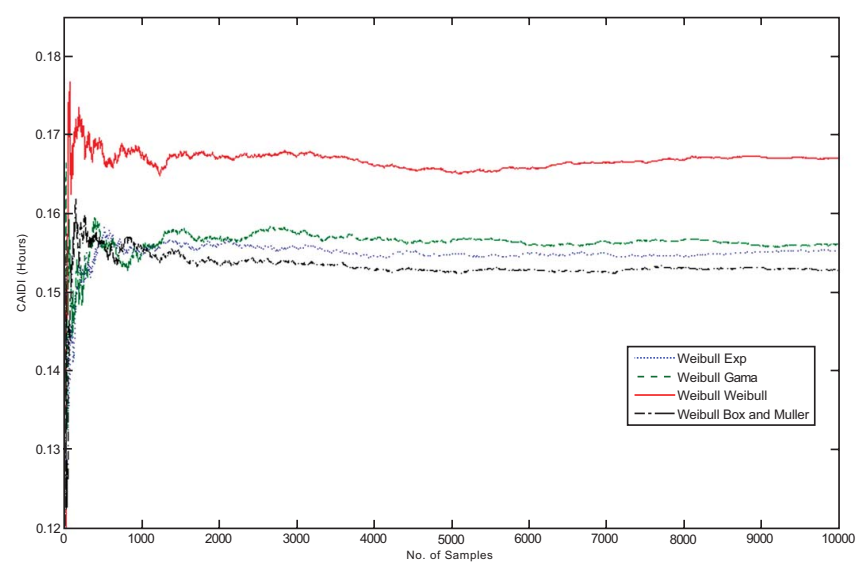

Fig. (6). Random operation (different pdf results of 2 DGs).
Carlo simulation convergence of CAIDI based on deterministic operating hours for the examined pdfs. A comparison between the results obtained using the deterministic and the random schemes are shown in Fig. (7).

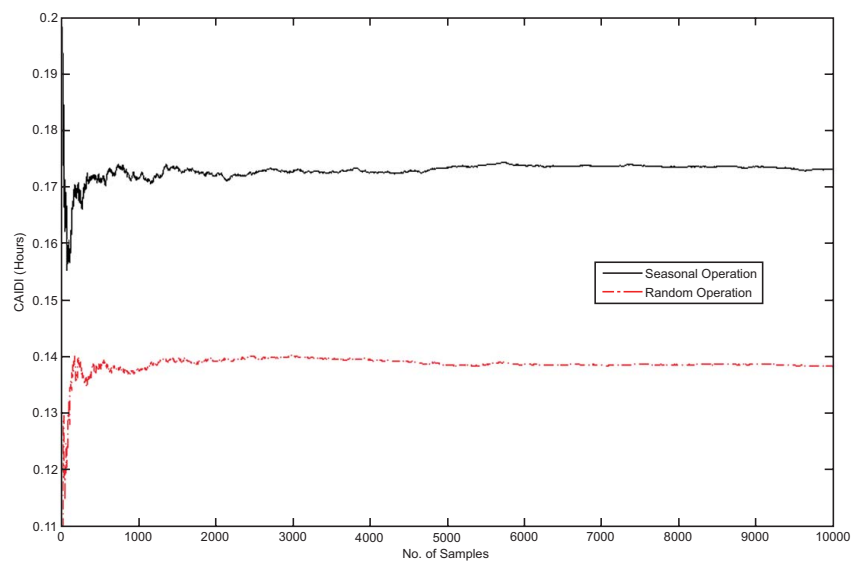

Fig. (7). A comparison between the estimated CAIDI at load point A.

The results obtained prove that as the number of experiments increases all the probability distribution functions converge to the same values. It is concluded that the difference in the result of the two proposed operation approaches used to evaluate the CAIDI for a given system is nearly 0.02 hours $(10 \%)$. This difference is considered to be slight and acceptable, which confirms the suitability of the random operating hour's schemes to model the operation of the DG units for reliability studies.

\section{CONCLUSIONS}

The impact of the generation techniques on the reliability of the distributed generation system is thoroughly investigated in this paper. The results showed that Hydro GT has recorded the lowest interruptions times and durations with respect to the other two GT, while the combustion turbine generation GT is preferred as an alternative or a back-up supply if its reliability indices are compared to that of wind energy GT. This is due to the stability in the level of power generated by the combustion turbine GT. Five generation techniques were examined in this research, four conventional types and wind energy generators as an example of renewable sources. The results obtained showed that wind farms do not have continuous and fixed level for power generation. The wind speed variations still a challenge for the power network designers. However, the use of wind energy as a DG tends to decrease the interruptions durations and may lead to frequent interruptions.

Two approaches were proposed to describe the anticipated operation of generating units taking into consideration seasonal and random operation. Seasonal operation schedule for DGs is considered to be more applicable than the unlimited operation mode. The proposed random operation technique to study the performance of distributed systems converged to the same results obtained by the seasonal operation with an acceptable percentage of error. 


\section{APPENDIX A}

\section{Reliability Data}

A.1. Data of the Reliability Test system (IEEE-RTS)

\begin{tabular}{|c|c|c|c|c|c|}
\hline \multirow{2}{*}{ Gen. set } & \multirow{2}{*}{ Size(Mw) } & GT & \multirow{2}{*}{$\begin{array}{c}\text { No. of } \\
\text { units }\end{array}$} & MTTF & MTTR \\
\cline { 5 - 6 } & & & (Hours) & (Hours \\
\hline \hline 1 & 12 & Fossil(Oil) & 5 & 2940 & 60 \\
\hline 2 & 20 & Comb. & 4 & 450 & 50 \\
\hline 3 & 50 & Hydro & 6 & 1980 & 20 \\
\hline 4 & 76 & Fossil(coal) & 4 & 1960 & 40 \\
\hline 5 & 100 & Fossil(oil) & 3 & 1200 & 50 \\
\hline 6 & 155 & Fossil(coal) & 4 & 960 & 40 \\
\hline 7 & 197 & Fossil(oil) & 3 & 950 & 50 \\
\hline 8 & 350 & Fossil(coal) & 1 & 1150 & 100 \\
\hline 9 & 400 & Nuclear & 2 & 1100 & 150 \\
\hline
\end{tabular}

\section{A.2. Specifications of the Used Wind Turbine Generator}

Cut in velocity $=5 \mathrm{~m} / \mathrm{s}$

Cut off velocity $=22 \mathrm{~m} / \mathrm{s}$

Rated velocity $=15 \mathrm{~m} / \mathrm{s}$

Rated power $=2.5 \mathrm{MW}$

\section{A.3. Wind Farm Generator Data}

\begin{tabular}{|c|c|}
\hline Generated Power & Duration (hours/year) \\
\hline \hline None & 94 \\
\hline $1 \mathrm{Mw}$ up to $1.3 \mathrm{Mw}$ & 1934 \\
\hline $0.6 \mathrm{Mw}$ and less & 3638 \\
\hline $0.4 \mathrm{Mw}$ and less & 4798 \\
\hline $0.2 \mathrm{Mw}$ and less & 6336 \\
\hline
\end{tabular}

\section{A.4. Reliability Data of the Feeder Under Study}

\begin{tabular}{|c|c|c|c|}
\hline Section length & Type & MTTF & MTTR \\
\hline \hline 2 miles & Main Feeder & 43800 & 3 \\
\hline 3 miles & Main Feeder & 29200 & 3 \\
\hline 1 mile & Main Feeder & 87600 & 3 \\
\hline All lengths (approximation) & Lateral Feeders & 17520 & 1 \\
\hline
\end{tabular}

\section{A.5. Probability Distribution Functions (Pdf) [16]}

\section{Exponential PDF:}

$\mathrm{TTF}=-\mathrm{MTTF} \cdot \ln \mathrm{X}_{1}$

TTR $=-M T T R \cdot \ln X_{2}$
Where $X_{I}$ and $X_{2}$ are random numbers between 0 and 1

2. Wie-Bull PDF:

$\mathrm{TTF}=\left((\mathrm{MTTF}) *-\ln \left(\mathrm{u}_{\mathrm{a}}\right)^{1 / \mathrm{beta}}\right)$

$\mathrm{TTR}=\left((\mathrm{MTTR})^{*}-\ln \left(\mathrm{u}_{\mathrm{b}}\right)^{1 / \mathrm{beta}}\right)$

Where $\mathrm{u}_{\mathrm{a}}$ and $\mathrm{u}_{\mathrm{b}}$ are random numbers between 0 and 1

3. Box and Muller PDF:

$$
\begin{aligned}
& \mathrm{X} 1=\left[\sqrt{\left.-2 * \log \left(\mathrm{u}_{\mathrm{a}}\right)\right)}\right] *\left[\cos \left(2 * \partial * \mathrm{u}_{\mathrm{a}}\right)\right] \\
& \mathrm{X} 2=\left[\sqrt{\left.-2 * \log \left(\mathrm{u}_{\mathrm{b}}\right)\right)}\right] *\left[\sin \left(2 * \partial * \mathrm{u}_{\mathrm{b}}\right)\right] \\
& \mathrm{TTF}=\mathrm{MTTF} * \mathrm{X} 1 \\
& \mathrm{TTR}=\mathrm{MTTR} * \mathrm{X} 2
\end{aligned}
$$

Where $\mathrm{u}_{\mathrm{a}}$ and $\mathrm{u}_{\mathrm{b}}$ are random numbers between 0 and 1 .

4. Gamma PDF:

$$
\begin{aligned}
& \mathrm{TTF}=\mathrm{MTTF} * \ln \left(\prod_{1}^{\mathrm{T}} \mathrm{U}\right) \\
& \mathrm{TTR}=\mathrm{MTTR} * \ln \left(\prod_{1}^{\mathrm{T}} \mathrm{U}\right)
\end{aligned}
$$

Where $\mathrm{U}$ is vector whose length is beta composed of zeros and ones, created randomly.

\section{REFERENCES}

[1] IEEE Guide for Electric Power Distribution Reliability Indices, IEEE Std 1366, USA: IEEE Power Engineering Society, 2001.

[2] J. E. Kim and J. S. Hwang, "Islanding detection method of distributed generation units connected to power distribution system", Proceeding of IEEE PES Summer Meeting, 2001, pp. 643647.

[3] Resource Dynamics Corporation, Assessment of Distributed Generation Technology Applications, Prepared for: Maine Public Utilities Commission, February 2001.

[4] T. Ackermann, G. Anderson, and L. Soder, "Distributed generation: a definition", Electric Power Systems Research, vol. 57, pp. 195-204, 2001.

[5] R. Billinton and W. Li, Reliability Assessment of Electric Power Systems Using Monte Carlo Methods, New York and London: Plenum Publishing, 1994.

[6] C. Singh and A. Lago-Gonzalez, "Reliability modeling of generating system including unconventional energy sources", IEEE Transactions Power Apparatus and Systems, vol. 104, No. 5, pp. 1049-1056, May 1985.

[7] R. Billinton and Peng Wang, "Teaching distribution system reliability evaluation using monte carlo simulation", IEEE Transactions on Power Systems, vol. 14, No. 2, May 1999.

[8] A. B. Attya, Y. G. Hegazy and M. A. Mostafa, "Variation of reliability indices with generation techniques applied", 7th WSEAS International Conference on Electric Power Systems, High Voltages, Electric Machines, Venice, Italy, November 21-23, 2007, pp. 264-269.

[9] A.B. Attya, Y. G. Hegazy and M. A. Mostafa, "Evaluation of system reliability using seasonal and random operation techniques", Proceeding of 2008 IEEE PES General Meeting, July, Pittsburgh, USA, 2008.

[10] Y.G. Hegazy, M.M.A. Salama and A.Y. Chikhani, "Distributed generation and distribution system reliability", Proceedings of the power systems 2002 conference: Impact of Distributed Generation, Clemson, SC, March 2002.

[11] Y.G.Hegazy, M.M.A Salama and A.Y. Chikhani, "Adequacy assessment of distributed generation systems using monte carlo simulation", IEEE Transactions of Power Systems, vol. 18, No. 1, pp. 48-52, Feb. 2003. 
[12] A. A. Chowdhury, S.K. Agarwal, and D.O. Koval, "Reliability modeling of distributed generation in conventional distribution systems planning and analysis", IEEE Transactions on Industry Applications, vol. 39, No. 5, pp. 1493-1498, Sep. 2003.

[13] R.C. Dugan and S.R. Price, "Issues for distributed generation in the US", Proceedings of IEEE Power Engineering Society Summer Meeting, vol. 1, 2002, pp. 121-131.

[14] R.E. Brown, "Modeling the reliability impact of distributed generation", Proceedings of IEEE Power Engineering Society Summer Meeting, vol. 1, 2002, pp. 442-446.
[15] McDermott, and R.C. Dugan, "Distributed generation impact on reliability and power quality indices" Proceedings of the IEEE Rural Electric Power Conference, 2002, pp. D3 -1-7.

[16] Billinton, R. and Li, W., Reliability Assessment of Electric Power Systems Using Monte Carlo Methods, New York and London: Plenum Publishing, 1994.

Received: August 10, 2008

Revised: October 31, 2008

Accepted: March 11, 2009

(C) Attya et al.; Licensee Bentham Open.

This is an open access article licensed under the terms of the Creative Commons Attribution Non-Commercial License (http://creativecommons.org/licenses/by-nc/3.0/) which permits unrestricted, non-commercial use, distribution and reproduction in any medium, provided the work is properly cited. 